\title{
Editorial
}

\section{When complex worlds collide: retinoic acid and apoptosis}

\author{
Jonathan D. Ashwell \\ Laboratory of Immune Cell Biology, National Cancer Institute, National Institutes \\ of Health, Bethesda, Maryland 20892-1152, USA
}

Retinoids are lipid-soluble compounds derived from, and including, vitamin A (retinol) and synthetic derivatives thereof. Retinol is delivered to cells bound to serum retinol binding protein (RBP), and once taken up it binds to cellular retinol binding protein (CRBP). The retinol-CRBP complex serves as a substrate for enzymes involved in retinoid metabolism, one product of which is retinoic acid (RA), the metabolite that mediates most of the non-visual functions of vitamin $A$ (Napoli, 1996). RA binds cellular retinoic acid binding protein (CRABP), a molecule that appears to function as a regulator of RA metabolism and perhaps its access to the nucleus (Napoli, 1996). Once in the nucleus, RA binds nuclearresident transcription factors known as retinoic acid receptors (RARs) or retinoid $X$ receptors (RXRs) (referred to collectively as $\mathrm{RA}$ receptors), each family being composed of at least three different genes (Chambon, 1996). Much of the difficulty in understanding the interesting (and complicated) biological functions of these receptors arises from the fact that the two RA receptor families, which can homodimerize and heterodimerize not just with each other but also other nuclear hormone receptors, have different ligand-binding specificities: RXRs bind 9-cis RA with high affinity, while RARs bind both 9cis and its stereoisomer all-trans RA with high affinity (Heyman et al, 1992; Levin et al, 1992). As detailed in two reviews in this issue of Cell Death and Differentiation, the recent development of RA receptor-specific retinoids is making it possible to clarify the roles of these receptors in different biological processes (Nagy et al, 1998; Szondy et al, 1998).

Like thyroid hormone and vitamin $D_{3}$ receptors, RA receptors bind to DNA response elements composed of two direct repeat (DR) half-sites with a consensus sequence of AGGTCA (Mangelsdorf et al, 1991; Umesono et al, 1991; $\mathrm{Yu}$ et al, 1991). Which receptors bind and mediate transactivation is determined by the spacing between the half-sites. RAR/RXR heterodimers bind to direct repeats separated by five nucleotides (DR5), while RXR/RXR homodimers bind to direct repeats separated by one nucleotide (DR1). Although RAR/RXR heterodimers also bind DR1 elements, they do not transactivate gene transcription at these sites, implying that RARs are inhibitory in this context. It appears that the polarity of protein binding to the half sites (that is, the position of each element of the RAR/RXR heterodimer on the DNA) is an important determinant of transactivation potential. In DR1-, but not DR5- (Kurokawa et al, 1993; Zechel et al, 1994), containing promoters, the RAR binds upstream of the RXR and allosterically prevents its RXR partner from binding ligand (Kurokawa et al, 1994).

An interesting and important feature of RA receptors is that in the unactivated (unliganded) state they bind to DNA and actively repress transcription of target genes. It has become apparent that they do not do so alone, but rather interact with distinct groups of corepressors (and coactivators, in the liganded state) to mediate their function. The basis for this lies in the exciting observation that chromatin conformation, which can profoundly affect the transcriptional process, is altered in biologically meaningful ways by acetylation (reviewed in Wade et al, 1997). In particular, the $\mathrm{NH}_{2}$-terminal tails of core histones are exposed on the outside of nucleosomes, and their acetylation on lysine residues decreases their charge and therefore binding to DNA. The ensuing changes in nucleosomal packing and chromatin conformation results in increased access of transacting factors and components of the basal transcriptional machinery to the local DNA (Luger et al, 1997). RA receptors and their associated factors make use of reversible acetylation to regulate target genes. Among the factors (corepressors) that bind RA receptors in the absence of ligand are SMRT (silencing mediator of retinoic acid and thyroid hormone receptors) or N-Cor (nuclear corepressor), $\mathrm{mSin} 3 \mathrm{~A}$, and the histone deacetylase HDAC1 (Heinzel et al, 1997; Nagy et al, 1997). Thus, unbound RA receptors recruit a deacetylating complex to their target genes, maintaining the local chromatin in an unfavorable conformation for transcription. Upon binding of RA, the inhibitory complex dissociates and a new set of factors (coactivators) bind. These include p300 and its homolog CBP (CREB-binding protein), P/CAF (p300/CBP-associated factor), and ACTR (and its related proteins SRC-1 and GRIP/TIF2). p300/CBP, P/CAF, and ACTR/SRC-1 have all been shown to have intrinsic histone acetyltransferase (HAT) activity (Bannister and Kouzarides, 1996; Chen et al, 1997; Ogryzko et al, 1996; Spencer et al, 1997; Yang et al, 1996). Thus, a major mechanism by which RA receptors regulate transcription of target genes is by controlling the reversible covalent modification of histones and thereby neighboring chromatin conformation. The fact that RA receptor coactivators and corepressors also associate with other nuclear factors offers a host of opportunities for functional interactions (cross-talk) between these transcriptional regulators.

Among the many biological properties of retinoids are their potent effects on cell differentiation and viability. One of several clinically important examples is acute promyelocytic leukemia (APL), for which RA is one of the cornerstones of therapy (Scheinberg et al, 1997). The 
most common form of APL is caused by a reciprocal chromosomal translocation resulting in the production of a fusion protein composed of $\mathrm{RAR} \alpha$ and $\mathrm{Pml}$, a nuclear phosphoprotein of unknown function (Chang et al, 1995). Transgenic mice that express the PMLRAR $\alpha$ fusion gene develop APL and, like their human counterparts, respond to therapy with RA (Brown et al, 1997; He et al, 1997). In this case, the therapeutic efficacy of RA is thought to be primarily due to its ability to promote differentiation of the promyelocytic cells. Based upon its 'anti-proliferative' effects, the use of RA as an adjunct in the treatment of a variety of other malignancies is being explored. The most commonly used form, all-trans RA, has limited usefulness in long-term therapy, however, because of its increased metabolic clearance over time with a resulting decrease in the plasma levels achieved (Adamson et al, 1993). It is likely that this problem can be overcome with synthetic retinoids that do not induce their own metabolism (Miller et al, 1997).

Two reviews in the current issue of Cell Death and Differentiation deal with a particularly efficient mechanism for controlling cell growth: apoptosis. RA, like glucocorticoids, have the distinction of both promoting and inhibiting apoptosis, the outcome depending upon the cell type, the specificity of the retinoid, and the presence or absence of other stimuli. RA prevents the activation-induced apoptosis of $T$ cells and thymocytes, in the former case, at least, by inhibiting the upregulation of Fas ligand expression (Yang et al, 1995b). The finding that interactions between Fas and upregulated Fas ligand are responsible for the ex-vivo death of lymphocytes from HIV-infected individuals (Bäumler et al, 1996; Yang et al, 1997), and that this is inhibited by oral administration of RA (Yang et al, 1995a), may provide another potentially therapeutic role for RA. In the absence of activation, RA can also induce the death of thymocytes (Fesus et al, 1995). The biologic relevance of this is unclear, since at physiologic concentrations RA does not cause thymocyte apoptosis, and although RA does appear to enhance glucocorticoid-mediated thymocyte death the effect is, at best, modest (Fesus et al, 1995; Iwata et al, 1992). Fesus and colleagues detail this phenomenon, and using $R A$ receptor-selective retinoids explore the different (antagonistic) roles played by RAR $\alpha$ and RARy (Szondy et al, 1998). Davies and coworkers review the mechanisms of RA action, both in vitro and in vivo (Nagy et al, 1998). A particularly interesting topic is the role of retinoids in the transcriptional regulation of tissue transglutaminase, an intracellular enzyme that cross-links proteins and which is upregulated during apoptosis.

The potent biological effects of retinoids have been known for many years. What is relatively new is the appreciation that different RAs, binding different members of a complex receptor superfamily, have such diverse and even antagonistic activities. Add to this the fact that coactivators and corepressors of RA receptor transcriptional activity are shared with other receptors/transactivation factors, and it is clear that the potential for fine-tuning biological responses are enormous. There is no doubt that dissecting and elucidating the means by which retinoids promote, and in some cases inhibit, apoptosis will provide fascinating insights into one of the most important decisions a cell must make: whether to live or to die.

\section{References}

Adamson PC, Boylan JF, Balis FM, Murphy RF, Godwin KA, Gudas LJ and Poplack DG (1993) Time course of induction of metabolism of all-trans-retinoic acid and the up-regulation of cellular retinoic acid-binding protein. Cancer Res. 53: 472476

Bannister AJ and Kouzarides T (1996) The CBP co-activator is a histone acetyltransferase. Nature 384: 641-643

Bäumler CB, Böhler T, Herr I, Benner A, Krammer PH and Debatin K-M (1996) Activation of the CD95 (APO-1/Fas) system in T cells from human immunodeficiency virus type-1-infected children. Blood 88: 1741-1746

Brown D, Kogan S, Lagasse E, Weissman I, Alcalay M, Pelicci PG, Atwater S and Bishop JM (1997) A PMLRAR $\alpha$ transgene initiates murine acute promyelocytic leukemia. Proc. Natl. Acad. Sci. USA 94: 2551-2556

Chambon $\mathrm{P}$ (1996) A decade of molecular biology of retinoic acid receptors. FASEB J. 10: $940-954$

Chang KS, Fan YH, Andreeff M, Liu J and Mu ZM (1995) The PML gene encodes a phosphoprotein associated with the nuclear matrix. Blood 85: 3646-3653

Chen H, Lin RJ, Schiltz RL, Chakravarti D, Nash A, Nagy L, Privalsky ML, Nakatani Y and Evans RM (1997) Nuclear receptor coactivator ACTR is a novel histone acetyltransferase and forms a multimeric activation complex with P/CAF and CBP/p300. Cell 90: 569-580

Fesus L, Szondy Z and Uray I (1995) Probing the molecular program of apoptosis by cancer chemopreventive agents. J. Cell. Biochem. Suppl. 22: 151-161

He LZ, Tribioli C, Rivi R, Peruzzi D, Pelicci PG, Soares V, Cattoretti G and Pandolfi PP (1997) Acute leukemia with promyelocytic features in PML/RAR $\alpha$ transgenic mice. Proc. Natl. Acad. Sci. USA 94: 5302-5307

Heinzel T, Lavinsky RM, Mullen TM, Soderstrom M, Laherty CD, Torchia J, Yang WM, Brard G, Ngo SD, Davie JR, Seto E, Eisenman RN, Rose DW, Glass CK and Rosenfeld MG (1997) A complex containing N-CoR, mSin3 and histone deacetylase mediates transcriptional repression. Nature 387: 43-48

Heyman RA, Mangelsdorf DJ, Dyck JA, Stein RB, Eichele G, Evans M and Thaller C (1992) 9-Cis retinoic acid is a high affinity ligand for the retinoid $X$ receptor. Cell 68: $397-406$

Iwata M, Mukai M, Nakai Y and Iseki R(1992) Retinoic acids inhibitactivation-induced apoptosis in T cell hybridomas and thymocytes. J.Immunol. 149: 3302-3308

Kurokawa R, Yu VC, Naar A, Kyakumoto S, Han Z, Silverman S, Rosenfeld MG and Glass CK (1993) Differential orientations of the DNA-binding domain and carboxy-terminal dimerization interface regulate binding site selection by nuclear receptor heterodimers. Genes Dev. 7: 1423-1435

Kurokawa R, DiRenzo J, Boehm M, Sugarman J, Gloss B, Rosenfeld MG, Heyman RA and Glass CK (1994) Regulation of retinoid signalling by receptor polarity and allosteric control of ligand binding. Nature 371: 528-531

Levin AA, Sturzenbecker LJ, Kazmer S, Bosalkowski T, Huselton C, Allenby G, Speck G, Kratzeisen Cl, Rosenberger M, Lovey A and Grippo J (1992) 9-Cis retinoic acid stereoisomer binds and activates the nuclear receptor $\mathrm{RXR} \alpha$. Nature 355: 359-361

Luger K, Mäder AW, Richmond RK, Sargent DF and Richmond TJ (1997) Crystal structure of the nucleosome core particle at 2.8 Á resolution. Nature 389: $251-$ 260

Mangelsdorf DJ, Umesono K, Kliewer SA, Borgmeyer U, Ong ES and Evans RM (1991) A direct repeat in the cellular retinol-binding protein type II gene confers differential regulation by RXR and RAR. Cell 66: 555-561

Miller VA, Benedetti FM, Rigas JR, Verret AL, Pfister DG, Straus D, Kris MG, Crisp M, Heyman R, Loewen GR, Truglia JA and Warrell RPJ (1997) Initial clinical trial of a selective retinoid $X$ receptor ligand, LGD1069. J. Clin. Oncol. 15: 790-795

Nagy L, Kao HY, Chakravarti D, Lin RJ, Hassig CA, Ayer DE, Schreiber SL and Evans RM (1997) Nuclear receptor repression mediated by a complex containing SMRT, mSin3A, and histone deacetylase. Cell 89: 373-380

Nagy L, Thomazy VA, Heyman RA and Davies PJA (1998) Retinoid-induced apoptosis in normal and neoplastic tissues. Cell. Death Differ. 5: 11-19

Napoli JL (1996) Retinoic acid biosynthesis and metabolism. FASEB J. 10: $993-$ 1001 
Ogryzko VV, Schiltz RL, Russanova V, Howard BH and Nakatani Y (1996) The transcriptional coactivators $\mathrm{p} 300$ and $\mathrm{CBP}$ are histone acetyltransferases. Cell 87: 953-959

Scheinberg DA, Maslak P and Weiss M (1997) Acute leukemias. In Cancer: principles \& practice of oncology, DeVita, Jr. VT, Hellman S and Rosenberg SA, eds. (Philadelphia, PA: Lippincott-Raven Publishers) pp 2293-2320

Spencer TE, Jenster G, Burcin MM, Allis CD, Zhou J, Mizzen CA, McKenna NJ, Onate SA, Tsai SY, Tsai MJ and O'Malley BW (1997) Steroid receptor coactivator-1 is a histone acetylstransferase. Nature 389: 194-198

Szondy Z, Reichert U and Fésüs L (1998) Retinoic acids regulate apoptosis of $T$ lymphocytes through an interplay between RAR and RXR receptors. Cell. Death Differ. 5: 4-10

Umesono K, Murakami KK, Thompson CC and Evans RM (1991) Direct repeats as selective response elements for the thyroid hormone, retinoic acid, and vitamin D3 receptors. Cell 65: 1255-1266

Wade PA, Pruss D and Wolffe AP (1997) Histone acetylation: chromatin in action. Trends Biochem. Sci. 22: 128-132

Yang XJ, Ogryzko VV, Nishikawa J, Howard BH and Nakatani Y (1996) A p300/CBPassociated factor that competes with the adenoviral oncoprotein E1A. Nature 382: $319-324$
Yang Y, Bailey J, Vacchio MS, Yarchoan R and Ashwell JD (1995a) Retinoic acid inhibition of ex vivo HIV-associated apoptosis of peripheral blood cells. Proc. Natl. Acad. Sci. USA 92: 3051-3055

Yang Y, Mercep M, Ware CF and Ashwell JD (1995b) Fas and activation-induced Fas ligand mediate apoptosis of T cell hybridomas: inhibition of Fas ligand expression by retinoic acid and glucocorticoids. J. Exp. Med. 181: 1673-1682

Yang Y, Liu Z-H, Ware CF and Ashwell JD (1997) A cysteine protease inhibitor prevents activation-induced $T$ cell apoptosis and death of peripheral blood cells from HIV-infected individuals by inhibiting upregulation of Fas ligand. Blood 89: $550-557$

Yu VC, Delsert C, Andersen B, Holloway JM, Devary OV, Naar AM, Kim SY, Boutin JM, Glass CK and Rosenfeld MG (1991) RXR beta: a coregulator that enhances binding of retinoic acid, thyroid hormone, and vitamin $\mathrm{D}$ receptors to their cognate response elements. Cell 67: 1251-1266

Zechel C, Shen XQ, Chen JY, Chen ZP, Chambon P and Gronemeyer H (1994) The dimerization interfaces formed between the DNA binding domains of RXR, RAR and TR determine the binding specificity and polarity of the full-length receptors to direct repeats. EMBO J. 13: $1425-1433$ 